\title{
Skin blood flow as a predictor of intraventricular hemorrhage in very-low-birth-weight infants
}

\author{
Akio Ishiguro', Keiji Suzuki², Takashi Sekine ${ }^{3}$, Yousuke Sudo', Hidenori Kawasaki', Kanako Itoh'1, Masayo Kanai', Ineko Kato',
} Hisanori Sobajima' and Masanori Tamura'

BACKGROUND: Cardiovascular instability immediately after birth is associated with intraventricular hemorrhage (IVH) in very-low-birth-weight (VLBW) infants. For circulatory management, evaluation of organ blood flow is important. In this study, the relationship between peripheral perfusion within $48 \mathrm{~h}$ after birth and IVH was evaluated in VLBW infants.

METHODS: In this prospective observational study involving 83 VLBW infants, forehead blood flow (FBF) and lower-limb blood flow (LBF) were measured for $48 \mathrm{~h}$ after birth using a laser Doppler flowmeter. Blood flow was compared between infants with and without IVH. Multivariate logistic regression analysis was performed to identify the risk factors for IVH.

RESULTS: IVH developed in nine infants. In eight of these patients, IVH occurred after $24 \mathrm{~h}$. LBF was lower in infants with $\mathrm{IVH}$ at 18 and $24 \mathrm{~h}$ and increased to the same level as that of infants without IVH at $48 \mathrm{~h}$. Multivariate logistic regression analysis identified a correlation only between LBF and IVH at $18 \mathrm{~h}$. CONCLUSION: These findings were consistent with the hypoperfusion-reperfusion theory, which states that IVH develops after reperfusion subsequent to hypoperfusion. We speculate that measurement of skin blood flow in addition to systemic and cerebral circulation may be helpful in predicting IVH.

ntraventricular hemorrhage (IVH) is one of the major causes of long-term neurological disability in very-low-birth-weight (VLBW) infants. In almost $90 \%$ cases, IVH occurs in the first $4 \mathrm{~d}$ of life (1). Several studies found an association between cardiovascular instability immediately after birth and IVH in VLBW infants (2-6).

Circulatory management in the neonatal intensive care unit (NICU) mainly focuses on elevation of blood pressure $(6,7)$. Several studies have identified an association between hypotension and poor neurodevelopmental outcomes $(1,3)$. However, no data from randomized controlled trials have been available to support the assumption that treatment of hypotension has a beneficial effect on mortality rates or IVH incidence in preterm infants (9-11). The failure of this management strategy in improving prognosis may be related to the fact that improvement of perfusion pressure by elevation of blood pressure does not always correspond to an adequate increase in organ blood flow, although the ultimate goal of circulatory management is to maintain organ perfusion and $\mathrm{O}_{2}$ delivery.

The importance of evaluating systemic blood flow and blood flow to all organs is being increasingly recognized (12). Some recent studies have demonstrated correlations between poor outcomes and low blood flow or hypoperfusion of both vital and nonvital organs in preterm infants (13-16). Regarding peripheral perfusion, Dempsey et al. (17) suggested a correlation between poor outcome and clinical signs of peripheral hypoperfusion such as urinary output, capillary refill time, and skin color during the early neonatal period in preterm infants. Assessment of peripheral perfusion is an important part of the clinical exam, as impairment of peripheral perfusion is one of the early markers of the compensated phase of neonatal cardiovascular compromise. However, capillary refill time, the most frequently used parameter to assess peripheral perfusion in the clinical practice, is a poor predictor of low systemic blood flow. Therefore, use of a more objective, real-time, noninvasive marker of peripheral perfusion would be preferred, at least in the research setting.

In this study, the correlation between IVH following postnatal circulatory instability during the extrauterine transitional period and skin and subcutaneous blood flow was investigated. Blood flow measurements were performed using a laser Doppler flowmeter in VLBW infants treated for hypotension during the first $48 \mathrm{~h}$ after birth.

\section{RESULTS}

In total, 83 infants were included in this study. Head ultrasonography confirmed that no IVH had developed in 74 infants at $1-3,6,24$, and $48 \mathrm{~h}$ after birth and on postnatal days 4 and 7. Head ultrasonography was performed at least once a day in all infants with IVH. Head ultrasonography confirmed IVH in nine infants at $24 \mathrm{~h}(n=1)$, between 24 and $48 \mathrm{~h}(n=4)$, between 48 and $72 \mathrm{~h}(n=3)$, and on day $6(n=1)$. Among these, five infants progressed to severe IVH. In all cases of severe IVH, progression of IVH from grade 2 to 3 or 4 occurred after $48 \mathrm{~h}(n=2$ on day $3, n=2$ on day $4, n=1$ on day 6$)$. Infants

'Department of Neonatal Medicine, Center for Maternal, Fetal and Neonatal Medicine, Saitama Medical Center, Saitama Medical University, Kawagoe, Saitama, Japan; ${ }^{2}$ Department of Pediatrics, Tokai University School of Medicine, Isehara-shi, Japan; ${ }^{3}$ Department of Pediatrics, Toho University Ohashi Medical Center, Tokyo, Japan. Correspondence: Akio Ishiguro (akio-i@k4.dion.ne.jp) 
Table 1. Demographic characteristics of the infants

\begin{tabular}{lccl}
\hline Characteristic & IVH & No IVH & $P$ value \\
\hline$n$ & 9 & 74 & \\
Gestational age (weeks) & $26.0(23.4-27.7)$ & $27.6(23.3-34.3)$ & 0.009 \\
Birth weight (grams) & $726(416-1186)$ & $805(374-1478)$ & 0.55 \\
Female & $3(33 \%)$ & $45(62 \%)$ & 0.15 \\
Preeclampsia & $1(11 \%)$ & $12(16 \%)$ & 1.0 \\
Antenatal steroid & $3(33 \%)$ & $50(68 \%)$ & 0.07 \\
Cesarean section & $8(89 \%)$ & $69(93 \%)$ & 1.0 \\
Ventilated & $8(89 \%)$ & $59(80 \%)$ & 0.68 \\
Apgar score & & & \\
1 min & $4(3-5)$ & $5(3-7)$ & 0.11 \\
5 min & $7(6,7)$ & $8(6-9)$ & 0.04 \\
Dopamine administration & $9(100 \%)$ & $69(81 \%)$ & 0.35 \\
Maximum dose of dopamine & $6.2(4.9-21.0)$ & $4.8(0-20.7)$ & 0.02 \\
Volume expander & $2(22 \%)$ & $6(8 \%)$ & 0.21 \\
administration & & & \\
\hline
\end{tabular}

Values are expressed as number (\%) or median (range) unless otherwise indicated. IVH, intraventricular hemorrhage.

values are expressed as median (25\%-75\% quartiles).
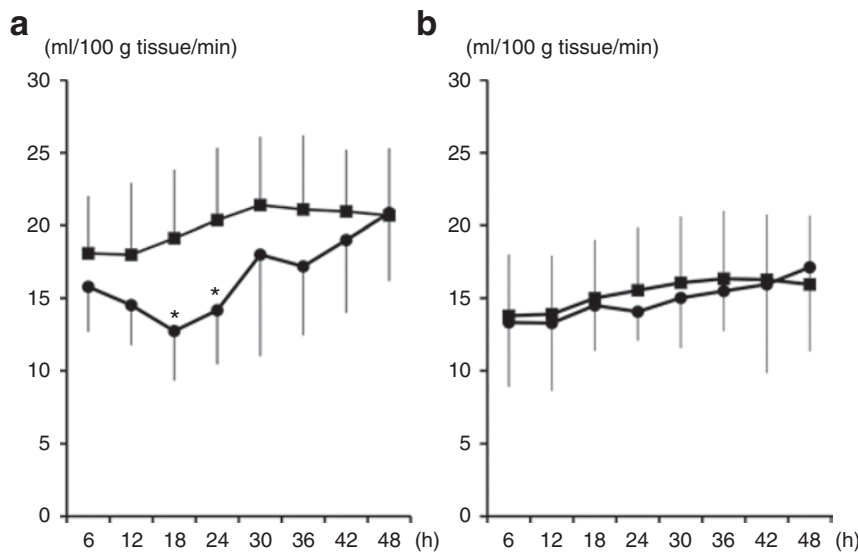

Figure 1. Temporal changes in skin and subcutaneous blood flow. (a) Lower-limb blood flow (LBF) in infants with and without intraventricular hemorrhage (IVH). (b) Forehead blood flow (FBF) in infants with and without IVH. Filled squares, without IVH $(n=74)$; filled circles, with IVH $(n=9)$. Due to infant death $(n=1)$ and due to temporary removal and displacement of the blood flow probe for interventions, some data were lost. The values were therefore calculated from available data ( $\mathrm{LBF}, n=72$, $n=71$, and $n=71$ at 30,36 , and $42 \mathrm{~h}$, respectively, in infants without IVH; $n=8, n=7, n=7, n=7$, and $n=8$ at $18,30,36,42$, and $48 \mathrm{~h}$, respectively, in infants with IVH; FBF, $n=71, n=70, n=69, n=70, n=69, n=66, n=$ 67 , and $n=69$ at $6,12,18,24,30,36,42$, and $48 \mathrm{~h}$, respectively, in infants without IVH; $n=8, n=7, n=7, n=7$, and $n=8$ at $18,30,36,42$, and $48 \mathrm{~h}$, respectively, in infants with IVH). Differences between groups, ${ }^{*} P<0.006$ (Bonferroni correction $P$-value criteria $<0.006$ ).

with IVH were born at earlier gestational age, had lower 5-min Apgar scores, and received higher dopamine doses (Table 1).

No significant changes were made in the dopamine dose administered to infants with and without IVH. Mean values (SD) in $\mu \mathrm{g} \cdot \mathrm{kg}^{-1} \cdot \mathrm{min}^{-1}$ were as follows: 9.0 (7.4), 10.7 (7.5), and 8.2 (6.2) at 6,24 , and $48 \mathrm{~h}$, respectively; and 4.2 (3.4), 5.0 (4.4),

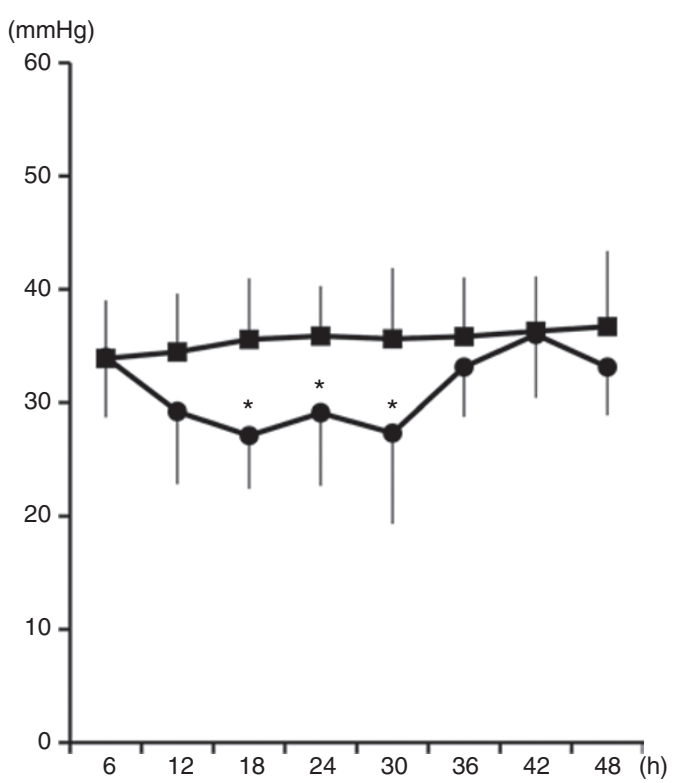

Figure 2. Temporal changes in the mean arterial blood pressure. Differences between groups, ${ }^{*} P<0.006$ (Bonferroni correction $P$-value criteria $<0.006)$. Filled squares, without intraventricular hemorrhage (IVH) $(n=74)$; filled circles, with IVH $(n=9)$. Due to temporary removal and displacement of the blood flow probe for interventions and due to discontinuity by death, some data were lost. Values were therefore calculated from available data $(n=72, n=73$ at 36 and $42 \mathrm{~h}$, respectively, in infants without IVH; $n=8, n=8$, and $n=8$ at 36,42 , and $48 \mathrm{~h}$, respectively, in infants with IVH).

and $4.5(4.1)$ at 6,24 , and $48 \mathrm{~h}$, respectively. Epinephrine was administered to three of the nine (33\%) infants with IVH; in two of these, it was initiated between 24 and $48 \mathrm{~h}$ after birth.

\section{Differences in Lower-Limb Blood Flow (LBF), Forehead Blood Flow (FBF), and Mean Arterial Blood Pressure (MAP) Between Infants With and Without IVH}

The mean LBF at 18 and $24 \mathrm{~h}$ was lower in infants with IVH than in those without (18 h: 12.7 (3.4) $\mathrm{ml} / 100 \mathrm{~g}$ and 19.1 (4.7) $\mathrm{ml} / 100 \mathrm{~g}$ tissue weight $/ \mathrm{min}, P=0.0004 ; 24 \mathrm{~h}: 14.2$ (3.7) $\mathrm{ml} / 100 \mathrm{~g}$ and $20.4(5.0) \mathrm{ml} / 100 \mathrm{~g}$ tissue weight $/ \mathrm{min}$, $P=0.0005$; Bonferroni correction $P$-value criteria $<0.05 / 8=$ 0.006; Figure 1a). No difference in FBF was found between the groups at any time point (Figure $\mathbf{1 b}$ ).

MAP was lower in infants with IVH than in those without IVH at 18, 24, and $30 \mathrm{~h} \mathrm{(18} \mathrm{h:} 27$ (5) $\mathrm{mmHg}$ vs. 36 (5) $\mathrm{mmHg}$, $P<0.001 ; 24$ h: 31 (5) mmHg vs. 36 (5) $\mathrm{mmHg}, P=0.004 ; 30 \mathrm{~h}$ : 27 (8) $\mathrm{mmHg}$ vs. 36 (6) $\mathrm{mmHg}, P<0.001$; Bonferroni correction $P$-value criteria $<0.05 / 8=0.006$; Figure 2 ).

\section{Temporal Changes in LBF, FBF, and MAP}

In infants with IVH, LBF decreased until $18 \mathrm{~h}$, following which it gradually increased until $48 \mathrm{~h}$. At $42 \mathrm{~h}$, this increase was statistically significant (18 vs. $42 \mathrm{~h}, P<0.05$; Figure $1 \mathrm{a}$ ). In infants without IVH, no change in LBF was observed until $12 \mathrm{~h}$. Thereafter, LBF gradually increased until $30 \mathrm{~h}$. At $24 \mathrm{~h}$, the increase was statistically significant ( 6 vs. $24 \mathrm{~h}, P<0.01 ; 12$ vs. $24 \mathrm{~h}, P<0.01$; Figure 1a). After $30 \mathrm{~h}$, LBF remained unchanged until $48 \mathrm{~h}$. 

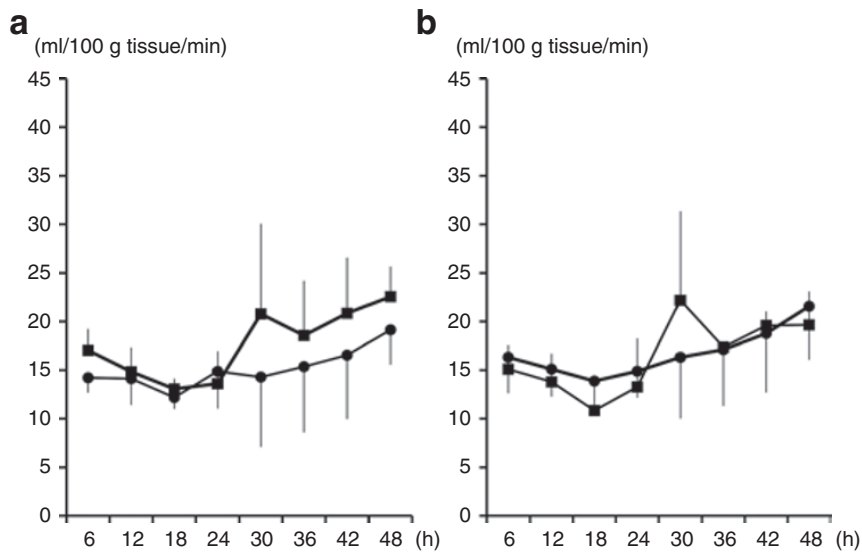

Figure 3. Lower-limb blood flow (LBF) and the timing of development and severity of intraventricular hemorrhage (IVH). (a) LBF in infants with IVH developing within $48 \mathrm{~h}$ and after $48 \mathrm{~h}$. Filled squares, IVH developing within $48 \mathrm{~h}(n=5)$; filled circles, IVH developing after $48 \mathrm{~h}(n=4)$. (b) LBF in infants with grade $2 \mathrm{IVH}$ and grade 3 or $4 \mathrm{IVH}$. Filled squares, grade $2 \mathrm{IVH}$ $(n=4)$; filled circles, grade 3 or $4 \mathrm{IVH}(n=5)$.

No significant temporal change in FBF was observed in infants with IVH. In infants without IVH, no change in FBF was observed until $12 \mathrm{~h}$. Thereafter, FBF gradually increased until $36 \mathrm{~h}$. At $24 \mathrm{~h}$, this increase was statistically significant ( 6 vs. $24 \mathrm{~h}, P<0.05$; Figure $1 \mathrm{~b}$ ), following which FBF remained unchanged until $48 \mathrm{~h}$.

In infants with IVH, MAP gradually decreased until $18 \mathrm{~h}$ and then remained unchanged until $30 \mathrm{~h}$. After $30 \mathrm{~h}$, MAP gradually increased until $42 \mathrm{~h}$ ( 12 vs. $42 \mathrm{~h}, P<0.05 ; 18$ vs. $42 \mathrm{~h}$, $P<0.01 ; 30$ vs. $42 \mathrm{~h}, P<0.05$; Figure 2$)$. In infants without IVH, MAP gradually increased until $48 \mathrm{~h}$. At $42 \mathrm{~h}$, this increase was statistically significant ( 6 vs. $42 \mathrm{~h}, P<0.05$; Figure 2 ).

\section{LBF and the Timing of Development and Severity of IVH}

No difference in LBF was detected at any time point between infants in whom IVH developed within $48 \mathrm{~h}$ and those in whom IVH developed between $48 \mathrm{~h}$ and day 7 (Figure 3a). No difference in LBF was found between infants with grade 2 IVH and infants with grade 3 or $4 \mathrm{IVH}$ at any time point (Figure $3 \mathbf{b}$ ).

\section{Risk Factors for IVH}

Univariate regression analysis was performed for the 12 demographic and clinical factors shown in Table 1 as well as MAP, FBF, and LBF at 6, 12, 18, and $24 \mathrm{~h}$. Univariate logistic regression analysis revealed that earlier gestational age, no antenatal steroid administration, higher maximum dose of dopamine, lower MAP at 12 and $18 \mathrm{~h}$, and lower LBF at 18 and $24 \mathrm{~h}$ were significant risk factors for IVH (Table 2). Multivariate regression analysis was performed at $18 \mathrm{~h}$, the lowest point for LBF and MAP during the study period. For the analysis, MAP at $18 \mathrm{~h}, \mathrm{FBF}$ at $18 \mathrm{~h}, \mathrm{LBF}$ at $18 \mathrm{~h}$, and factors in Table 2 with $P$ values of $<0.15$ between groups were selected. Multivariate logistic regression models revealed only LBF at $18 \mathrm{~h}$ as a significant risk factor (Table 2).

The receiver operator curves for MAP, FBF, and LBF at $18 \mathrm{~h}$ were determined. The area under the curve best cutoff value, sensitivity, specificity, and positive and negative
Table 2. Univariate and multivariate odds ratio for IVH

\begin{tabular}{|c|c|c|}
\hline Variable & Univariate OR (95\% Cl) & Adjusted OR (95\% Cl) \\
\hline $\mathrm{GA}^{\mathrm{a}}$ & $0.59(0.38-0.93) ; P=0.02$ & $1.95(0.53-7.23)$ \\
\hline Female sex & $0.39(0.09-1.74)$ & $0.22(0.009-5.60)$ \\
\hline $\begin{array}{l}\text { Antenatal } \\
\text { steroids }\end{array}$ & $0.16(0.03-0.85) ; P=0.03$ & $0.13(0.004-4.50)$ \\
\hline \multicolumn{3}{|l|}{ Apgar score } \\
\hline $1 \mathrm{~min}$ & $0.83(0.59-1.17)$ & $0.32(0.06-1.56)$ \\
\hline $5 \mathrm{~min}$ & $0.82(0.56-1.20)$ & $1.03(0.25-4.3)$ \\
\hline $\begin{array}{l}\text { Maximum dose } \\
\text { of dopamine }{ }^{b}\end{array}$ & $1.13(1.00-1.28) ; P=0.04$ & $1.08(0.81-1.44)$ \\
\hline MAP at $18 h^{c}$ & $0.69(0.57-0.85) ; P<0.001$ & $0.69(0.41-1.17)$ \\
\hline LBF at $18 \mathrm{~h}^{\mathrm{d}}$ & $0.58(0.39-0.84) ; P=0.005$ & $0.38(0.14-0.99) ; P=0.049$ \\
\hline FBF at $18 \mathrm{~h}^{d}$ & $0.97(0.80-1.17)$ & $1.24(0.74-2.06)$ \\
\hline \multicolumn{3}{|c|}{$\begin{array}{l}\text { Eight out of nine infants in the IVH group who developed IVH after } 24 \mathrm{~h} \text { were included } \\
\text { in this analysis. }\end{array}$} \\
\hline \multicolumn{3}{|c|}{$\begin{array}{l}\mathrm{Cl} \text {, confidence interval; } F \mathrm{FB} \text {, forehead blood flow; IVH, intraventricular hemorrhage; LBF, } \\
\text { lower-limb blood flow; MAP, mean arterial blood pressure; OR, odds ratio. }\end{array}$} \\
\hline \multicolumn{3}{|c|}{$\begin{array}{l}\text { 'OR for each additional week. }{ }^{b} \text { OR for each } 1 \mu \mathrm{\mu g} \cdot \mathrm{kg}-1 \cdot \mathrm{min}-1 \text { increment. }{ }^{\circ} \mathrm{OR} \text { for each } 1 \\
\mathrm{mmHg} \text { increment. }{ }^{\mathrm{d}} \mathrm{OR} \text { for each } 1 \mathrm{ml} / 100 \mathrm{~g} \text { tissue weight/min increment. }\end{array}$} \\
\hline
\end{tabular}

Table 3. MAP, LBF, and FBF at $18 \mathrm{~h}$ as predictors for IVH. ROC curve

\begin{tabular}{lccccccc} 
Value & AUC & SE & Cutoff & Sensitivity & Specificity & PPV & NPV \\
\hline MAP & 0.89 & 0.05 & 32 & 0.88 & 0.78 & 0.33 & 0.98 \\
LBF & 0.89 & 0.08 & 13.8 & 0.88 & 0.93 & 0.58 & 0.99 \\
FBF & 0.50 & 0.09 & 16.0 & 0.75 & 0.41 & 0.13 & 0.93
\end{tabular}

In total, 8/9 infants in the IVH group who developed IVH after $24 \mathrm{~h}$ were included in this analysis.

AUC, area under the curve; FBF, forehead blood flow; IVH, intraventricular hemorrhage; LBF, lower-limb blood flow; MAP, mean arterial blood pressure; NPV, negative predictive value; PPV, positive predictive value; ROC, receiver operating characteristic.

predictive values are shown in Table 3. Significantly higher area under the curve values were observed for LBF than for $\operatorname{FBF}(P=0.001)$, but not for MAP $(P=0.92)$.

\section{DISCUSSION}

The major finding of this study was that compared to infants without IVH, lower LBF values were observed until $24 \mathrm{~h}$ after birth in infants who developed IVH between $6 \mathrm{~h}$ and $7 \mathrm{~d}$ after birth. After $24 \mathrm{~h}$, these values increased to a level similar to (but not exceeding) those in infants without IVH at $48 \mathrm{~h}$. FBF and MAP also showed increasing trends over time in infants with IVH. Trends of FBF in infants with IVH were not statistically significant, probably because of the relatively small number of infants with IVH. Considering that IVH developed after $24 \mathrm{~h}$ in all cases but one, we conclude that IVH developed following a period of low blood flow and during a period of increased blood flow to a level not exceeding those in non-IVH infants. These findings are consistent with the hypoperfusion-reperfusion theory on the development of IVH, which states that IVH develops after reperfusion subsequent to hypoperfusion $(18,19)$. Lack of data after $48 \mathrm{~h}$ precluded evaluation of additional changes in blood flow after $48 \mathrm{~h}$ in infants in whom IVH developed after this time point. Causes of progression to 
severe IVH after $48 \mathrm{~h}$ were therefore unclear. However, low blood flow within $24 \mathrm{~h}$ and subsequent recovery of blood flow were observed in infants in whom IVH developed after $48 \mathrm{~h}$ and in infants in whom IVH progressed in severity. Assessment of peripheral blood flow and systemic blood pressure might identify very preterm neonates at higher risk for IVH during the transitional period.

The reasons behind the correlation between LBF and IVH and the lack of correlation between FBF and IVH are unclear. We previously reported a positive but weak correlation between LBF and superior vena cava blood flow (20). Superior vena cava blood flow has been used as a marker of upper-body systemic blood flow, including venous return from the brain (21). Previous studies reported an association between low superior vena cava blood flow within the first $48 \mathrm{~h}$ of life and IVH $(4,22)$. However, the extent to which superior vena cava blood flow accounts for cerebral blood flow in VLBW infants remains unclear. Cerebral blood flow is different from systemic and peripheral blood flow because it is regulated by several brain-specific factors such as cerebral autoregulation and flowmetabolism coupling. Correlations among systemic, cerebral, and peripheral blood flow must be investigated by simultaneous measurement of these parameters for better understanding of the mechanism underlying IVH development.

Previous research has suggested that because low cerebral blood flow and low blood pressure progress toward an ischemic threshold, the structural integrity of brain tissue is gradually compromised (23). Subsequent increase in blood flow may then cause bleeding from the destroyed vessels. On the basis of the data in the literature and the present findings, future interventional studies in very preterm infants might target preventing systemic and brain hypoperfusion immediately after delivery or, if hypoperfusion is not preventable, controlling the reperfusion rate of reperfusion for potential improvement of short- and long-term neurodevelopment.

Although several factors (including MAP) differed between the infants with and without IVH, after adjusting for these factors, only LBF correlated with IVH. The main goal of circulatory management in the NICU, especially for preterm infants, has been to maintain blood pressure using various therapeutic interventions. Several numerical standards of blood pressure have been suggested (24), and MAP has been a frequently used parameter in clinical settings. However, no previous studies have shown a decreased IVH incidence by management of blood pressure according to any standard. Therefore, this study was conducted to address this issue.

Blood pressure-related intervention was also provided to all infants participating in this study. Although MAP was lower in infants with IVH than in those without, MAP within the target range was achieved until the 24-h time point among all infants with IVH except one. Along with the data in the literature, the results of this study suggest that for the development of more effective treatment strategies to prevent IVH, parameters of blood flow along with blood pressure measurement need to be monitored and that this approach may include skin and subcutaneous blood flow measurement.
Findings of the present study also suggest that skin and subcutaneous blood flow might be a predictor of IVH. FBF was a less effective predictor of IVH than LBF. In our previous investigation on the hemodynamic effects of dopamine in VLBW infants (25), FBF was less informative than changes in LBF. No clear explanation for this finding exists at present; however, it may have been caused by differences in autonomic regulation between these two regions. The skin of the lower limb is innervated by sympathetic nerves alone, while blood flow in the facial skin is regulated by both sympathetic and parasympathetic nerves, such as the blood flow in the internal vital organs (26).

Frequent use of vasopressor-inotropes was a major limitation in this study. Dopamine was administered in the majority of infants in both groups, and the maximum dose was higher in infants with IVH than in those without. However, doses did not change significantly over time in either group. Concerns have been raised about the potential vasoconstrictive affects of dopamine (27). However, the results of our previous study (25) demonstrated that even if the dose was $10-20 \mu \mathrm{g} / \mathrm{kg} /$ min, dopamine significantly increased LBF in VLBW infants. Cardiovascular adrenergic receptor downregulation might explain the decreased cardiovascular responsiveness to dopamine in critically ill preterm infants (28). Therefore, the low blood flow in infants with IVH within $24 \mathrm{~h}$ was not considered to have resulted from a vasoconstrictive effect of dopamine. Epinephrine, which is considered to have a stronger vasoconstrictive effect than that of dopamine, was administered to three infants with IVH and may have decreased LBF. However, administration of this drug was initiated after $24 \mathrm{~h}$ in two of the three cases, and LBF was already below the cutoff value before administration in the other case. Therefore, epinephrine use in the present study may have had only a minimal effect on low LBF values in the infants with IVH within $24 \mathrm{~h}$.

In conclusion, the findings of this observational study suggest that decreased peripheral perfusion may predict the subsequent development of IVH in VLBW infants. These findings lend support to the hypothesis that hypoperfusion-reperfusion cycle plays a role in the pathogenesis of IVH. Larger studies using additional measures of brain (such as near-infrared spectroscopy) and systemic (echocardiography, electrical impedance) blood flow with LBF and FBF measurements are required to further clarify these findings.

\section{METHODS}

Written informed consent was obtained from the infants' parents immediately on admission to the NICU. This study was approved by the Ethical Committee of Saitama Medical Center, Saitama, Japan.

\section{Subjects}

This was a prospective observational study of infants born with a body weight of $<1,500 \mathrm{~g}$ at birth. Three hundred and eighty-five VLBW infants were born in the period between 1 September 2008 and 30 September 2012 and admitted to the NICU at Saitama Medical Center. To avoid interobserver error, the study was initiated when one specific investigator (A.I.) and the laser Doppler apparatus were both available $(n=111)$. Exclusion criteria included compromise other than prematurity, which could affect hemodynamics of the infants: congenital heart disease $(n=7)$, chromosomal and/or major 
anomalies ( $n=11)$, and Apgar scores of 0 at $1 \mathrm{~min}$, thus requiring epinephrine administration and/or chest compression $(n=4)$. Parents of three infants did not consent to participation in this study. At $6 \mathrm{~h}$ after birth, infants with IVH detected by head ultrasonography were excluded $(n=3)$ because early onset IVH is more likely to develop because of perinatal factors rather than postnatal factors (29). Eightythree infants were consequently included in the study.

All infants with hypotension received cardiac support. In the NICU, hypotension was defined as MAP below the lower 95\% confidence intervals found in a population study (30) or below the numerical number of the given patient's gestational age, which were almost equal. For infants with hypotension, dopamine or a single-volume expander $\left(10 \mathrm{ml} \cdot \mathrm{kg}^{-1}\right)$ was initially administered at the attending physician's discretion according to the infants' circulatory data such as heart rate, urine output, blood lactate level, and echocardiographic parameters. Dopamine was continuously infused via a peripherally inserted central catheter or umbilical venous line and usually initiated at a low to moderate dose $\left(3-10 \mu \mathrm{g} \cdot \mathrm{kg}^{-1} \cdot \mathrm{min}^{-1}\right)$. If blood pressure was not sufficiently restored, the dose of dopamine was incrementally increased by $2-5 \mu \mathrm{g} \cdot \mathrm{kg}^{-1} \cdot \mathrm{min}^{-1}$ up to $20 \mu \mathrm{g} \cdot \mathrm{kg}^{-1} \cdot \mathrm{min}^{-1}$. In some cases, an equal dose of dobutamine was alternatively added or an additional single-volume expander was administered. When all the above treatments were ineffective, epinephrine and/or corticosteroids were administered. All neonates were placed in an incubator during the study period. Skin temperature was maintained at $37.0 \pm 0.5^{\circ} \mathrm{C}$.

\section{Blood Flow Measurement}

A noninvasive continuous monitoring technique was used for measuring skin and subcutaneous blood flow, as described in our previous studies $(20,31)$. In brief, the system comprised a laser Doppler flowmeter (CDF-2000; Nexis, Fukuoka, Japan), a probe, and a computer. The probe was easily attached on the patients' skin using double-sided adhesive tape. The laser beams penetrated 3-4 $\mathrm{mm}$ into the skin, and the system measured the blood flow in the capillary vessels, venules, and arterioles within a specified hemispherical region. Probes were attached to the dorsum of the right or left foot, avoiding visible vessels. LBF and FBF were measured, and the data were stored in a computer for a 48 -h period. Once the data were collected, blood flow values were extracted at 10 -s intervals $30 \mathrm{~min}$ before and after each data point between 6 and $48 \mathrm{~h}$ at 6 -h intervals and averaged using 360 measurements for each.

\section{Cardiovascular Parameters}

Blood pressure was measured in all neonates. Systolic and diastolic pressure and MAP were recorded by nursing staff every hour for continuous blood pressure measurement $(n=50)$ and every $3 \mathrm{~h}$ using oscillometric methods $(n=33)$, confirming that the infants were at rest and free of any difficulties associated with the catheter line. Following this, data for every $6 \mathrm{~h}$ (one data point for each measurement) up to $48 \mathrm{~h}$ were collected for analysis.

\section{Head Ultrasonography}

Head ultrasonography was performed at $1-3,6,24$, and $48 \mathrm{~h}$ after birth and on postnatal days 4 and 7 using SONOS 5500 (Philips Medical Systems, Andover, MA) to confirm the presence and severity of IVH. In addition to these examinations, ultrasonography was also performed when attending physicians considered it necessary for follow-up of IVH or due to sudden changes in cardiovascular or respiratory conditions. Only IVH of grade 2 or more according to the Papile classification was defined as IVH in this study. Grade 3 or 4 IVH was defined as severe IVH.

\section{Data Analysis and Statistics}

Infants were divided into the following two groups: those with IVH and those without IVH. Background characteristics were compared between the two groups by the Mann-Whitney $U$-test or the $\chi^{2}$ test. A $t$-test with the Bonferroni correction was applied for multiple comparisons between groups. Comparisons of temporal changes in LBF, FBF, and MAP in each group were performed using one-way repeated ANOVA, and if the results were significant, the post hoc Tukey test was used. Univariate and multivariate regression analyses were performed to identify risk factors for IVH. For multivariate regression analysis, MAP, FBF, and LBF at each time point and demographic factors with $P$ values $<$
0.15 in univariate regression analysis were selected. In addition, receiver operator characteristic analysis was used to calculate the area under the curve, sensitivity, specificity, and positive and negative predictive values of LBF, FBF, and MAP at $18 \mathrm{~h}$ for the infants without IVH at each time point. Optimal cutoff values were determined by correspondence to a point on the receiver operator curve nearest to the upper left corner. All statistical values are shown as mean (SD) unless otherwise indicated, and a two-tailed $P$ value of $<0.05$ was considered statistically significant. Stat Flex (StatFlex; Artec, Osaka, Japan) was used for all statistical analyses.

\section{STATEMENT OF FINANCIAL SUPPORT}

This research was supported by a Saitama Medical University internal grant, Japan.

Disclosure: The authors have no financial relationships relevant to this manuscript to disclose. The authors have no conflicts of interest to disclose.

\section{REFERENCES}

1. Maden A, Hamrick SE, Ferriero DM. Central nervous system injury and neuroprotection. In: Taeusch HW, Ballard RA, Gleason CA, eds. Avery's Disease of the Newborn, 8th edn. Philadelphia, PA: Elsevier, 2004:965-92.

2. Bada HS, Korones SB, Perry EH, et al. Mean arterial blood pressure changes in premature infants and those at risk for intraventricular hemorrhage. J Pediatr 1990;117:607-14.

3. Meek JH, Tyszczuk L, Elwell CE, Wyatt JS. Low cerebral blood flow is a risk factor for severe intraventricular haemorrhage. Arch Dis Child Fetal Neonatal Ed 1999;81:F15-8.

4. Fanaroff AA, Fanaroff JM. Short- and long-term consequences of hypotension in ELBW infants. Semin Perinatol 2006;30:151-5.

5. Miletin J, Dempsey EM. Low superior vena cava flow on day 1 and adverse outcome in the very low birthweight infant. Arch Dis Child Fetal Neonatal Ed 2008;93:F368-71.

6. Vela-Huerta MM, Amador-Licona M, Medina-Ovando N, Aldana-Valenzuela C. Factors associated with early severe intraventricular haemorrhage in very low birth weight infants. Neuropediatrics 2009;40:224-7.

7. Al-Aweel I, Pursley DM, Rubin LP, Shah B, Weisberger S, Richardson DK. Variations in prevalence of hypotension, hypertension, and vasopressor use in NICUs. J Perinatol 2001;21:272-8.

8. Barrington KJ. Hypotension and shock in the preterm infant. Semin Fetal Neonatal Med 2008;13:16-23.

9. Ibrahim H, Sinha IP, Subhedar NV. Corticosteroids for treating hypotension in preterm infants. Cochrane Database Syst Rev 2011:CD003662.

10. Subhedar NV, Shaw NJ. Dopamine versus dobutamine for hypotensive preterm infants. Cochrane Database Syst Rev 2003:CD001242.

11. Osborn DA, Paradisis M, Evans N. The effect of inotropes on morbidity and mortality in preterm infants with low systemic or organ blood flow. Cochrane Database Syst Rev 2007: (doi: 10.1002/14651858.CD005090.pub2).

12. Cayabyab R, McLean CW, Seri I. Definition of hypotension and assessment of hemodynamics in the preterm neonate. J Perinatol 2009;29:Suppl 2:S58-62.

13. Osborn DA, Evans N, Kluckow M. Hemodynamic and antecedent risk factors of early and late periventricular/intraventricular hemorrhage in premature infants. Pediatrics 2003;112(1 Pt 1):33-9.

14. Osborn DA, Evans N, Kluckow M, Bowen JR, Rieger I. Low superior vena cava flow and effect of inotropes on neurodevelopment to 3 years in preterm infants. Pediatrics 2007;120:372-80.

15. Hunt RW, Evans N, Rieger I, Kluckow M. Low superior vena cava flow and neurodevelopment at 3 years in very preterm infants. J Pediatr 2004;145:588-92.

16. Tsuji M, Saul JP, du Plessis A, et al. Cerebral intravascular oxygenation correlates with mean arterial pressure in critically ill premature infants. Pediatrics 2000;106:625-32.

17. Dempsey EM, Al Hazzani F, Barrington KJ. Permissive hypotension in the extremely low birthweight infant with signs of good perfusion. Arch Dis Child Fetal Neonatal Ed 2009;94:F241-4.

18. Kluckow M, Evans N. Low superior vena cava flow and intraventricular haemorrhage in preterm infants. Arch Dis Child Fetal Neonatal Ed 2000;82:F188-94.

19. Noori S, Stavroudis TA, Seri I. Systemic and cerebral hemodynamics during the transitional period after premature birth. Clin Perinatol 2009;36:723-36, v. 


\section{Peripheral hypoperfusion and IVH

20. Ishiguro A, Sekine T, Suzuki K, et al. Changes in skin and subcutaneous perfusion in very-low-birth-weight infants during the transitional period. Neonatology 2011;100:162-8.

21. Kluckow M, Evans N. Superior vena cava flow in newborn infants: a novel marker of systemic blood flow. Arch Dis Child Fetal Neonatal Ed 2000;82:F182-7.

22. Kluckow M, Evans N. Low superior vena cava flow and intraventricular haemorrhage in preterm infants. Arch Dis Child Fetal Neonatal Ed 2000;82:F188-94

23. Cayabyab R, McLean CW, Seri I. Definition of hypotension and assessment of hemodynamics in the preterm neonate. J Perinatol 2009;29:Suppl 2:S58-62.

24. Osborn DA. Diagnosis and treatment of preterm transitional circulatory compromise. Early Hum Dev 2005;81:413-22.

25. Ishiguro A, Suzuki K, Sekine T, et al. Effect of dopamine on peripheral perfusion in very-low-birth-weight infants during the transitional period. Pediatr Res 2012;72:86-9.
26. Izumi H. Nervous control of blood flow in the orofacial region. Pharmacol Ther 1999;81:141-61.

27. Osborn D, Evans N, Kluckow M. Randomized trial of dobutamine versus dopamine in preterm infants with low systemic blood flow. J Pediatr 2002;140:183-91.

28. Seri I. Circulatory support of the sick preterm infant. Semin Neonatol 2001;6:85-95.

29. Osborn DA, Evans N, Kluckow M. Hemodynamic and antecedent risk factors of early and late periventricular/intraventricular hemorrhage in premature infants. Pediatrics 2003;112(1 Pt 1):33-9.

30. Lee J, Rajadurai VS, Tan KW. Blood pressure standards for very low birthweight infants during the first day of life. Arch Dis Child Fetal Neonatal Ed 1999;81:F168-70.

31. Ishiguro A, Sekine T, Kakiuchi S, et al. Skin and subcutaneous blood flows of very low birth weight infants during the first 3 postnatal days. J Matern Fetal Neonatal Med 2010;23:522-8. 